\title{
Conflicts of interest in medicine. CETREMI recommendation
}

Miguel Ángel Celis, José Halabe, Oscar Arrieta, Rubén Burgos, Carlos Campillo, Manuel De la Llata, Judith Domínguez, Sergio Islas, Luis Jasso, Alberto Lifshitz, Mucio Moreno, Ricardo Plancarte, Alejandro Reyes-Sánchez, Guillermo J. Ruiz-Argüelles, Antonio Soda, Emma Verástegui and Julio Sotēlo* Academia Nacional de Medicina de México, Comité de Ética y Transparencia en la Relación Médico-Industria, Mexico City, Mexico

\begin{abstract}
\end{abstract}
Conflicts of interest are situations in which judgment and integrity of medical decisions or actions are influenced by a secondary interest, often of an economic nature. The Committee of Ethics and Transparency in the Physician-Industry Relationship of the National Academy of Medicine of Mexico recognizes that these conflicts occur in health professionals' daily life, butalso in public and private institutions that provide health services, as well as in the academy and in research activities. Therefore, it is necessary to identify conflicting situations and always act in accordance with the patient's interest.

KEY WORDS: Conflict of interest. Medical ethics. Professional responsibility. Code of ethics.

Conflicts of interest in medicine are a reflection of situations where the judgment and integrity of medical decisions or actions are influenced by a secondary interest, often of an economic nature. A doctor, a company or health institution incur a conflict of interest when instead of complying with their function in accordance with professional or institutional ethics, or in accordance with regulatory and legal responsibilities, their decisions or actions are guided by their own or a third party's benefit. These conflicts may arise in numerous decisions involving health professionals.

Conflicts of interest develop both individually and collectively. In the field of health, commercial interests influence by modifying the consumption of medicines and on institutional practice of scientific groups, through financial marketing strategies. A reflection of this is the excess in the prescription of unnecessary drugs and the widespread practice of self-medication in the population, as a result of advertising campaigns in the media. Both behaviors can generate undesirable consequences in the patient and in collective health, such as drug interactions or adverse effects that causeiatrogenic conditions.

There may also be influence of the pharmaceutical and medical supplies industry on clinical research, through the funding of clinical trials with "innovattrve" drugs or "novel" technological devices, privileging commercial over social interest. Furthermore, pharmaceutical financial interest influences by hising health professionals for the conduction of studies, for their assessment and approval in committees. According to the results obtained in the research, the pharmaceutical industry even supports its publication in scientific journals.

Given this complex interaction, a deteriorated public image of some health professionals (not only doctors) ethical standards has been generated in society, which should be analyzed and addressed, and reinforce the principles of commercial disinterest and professional honesty of physicians in order to generate trust in society about the health professional and a better doctor-patient relationship.
Correspondence:

*Julio Sotelo

E-mail: jsotelo@ unam.mx
Date of reception: 06-05-2019

Date of acceptance: 18-06-2019

DOI: 10.24875/GMM.M20000343
Gac Med Mex. 2019;155:519-520

Contents available at PubMed

www.gacetamedicademexico.com

0016-3813/@ 2019 Academia Nacional de Medicina de México, A.C.. Published by Permanyer. This is an open access article under the CC BY-NC-ND license (http://creativecommons.org/licenses/by-nc-nd/4.0/). 
Primary interests of medicine are clearly established:

- Prevention of illness and injuries, as well as promotion and maintenance of health.

- Relief of the pain and suffering caused by illness.

- Assistance and healing of the sick and palliative care for those who cannot be cured.

- Avoid premature death and ensure a dignified death.

Recommendations of the Ethics and Transparency Committee in the Physician-Industry Relationship:

- Avoid conflict of interest in medical practice, in the relationship between doctor and patient due to the influence of the pharmaceutical and medical supplies industry, as well as by healthcare insurance companies, which might modify prescription habits to the detriment of patient's health or economic assets.

- Prevent companies or institutions that are commercially related to the doctor from influencing on the request for unnecessary examinations. Eliminate the dichotomy or participation of third parties in the financial benefits originated by medical interventions or by requesting studies.

- Oppose the pressure of insurance companies on the medical professional to reduce costs, and avoid studies or procedures without justification, or to the detriment of patient wellbeing.

- Do not allow the influence of promotional personnel on medical judgement or procedures. The interaction of doctors with representatives of the industry is widely extended, which is an understandable situation; however, these activities might introduce a disturbing bias in medical Feasoning, arising from the persuasion of financial interests over those of the patient, who should always be the center of attention.

- Avoid receiving presents or medical samples from medical representatives.

- Avoid the influence of patients or family members for the prescription of a certain medication or authorization of procedures. Medical decisiōns, in scenarios of diagnostic uncertainty, should be made in accordance with the best evidence-based clinical practice.

- Raise awareness (in the medical community and in particular among young doctors and students) that in case of clinical uncertainty and situations of potential conflict, it should be avoided for medical decisions to be primarily aimed at reducing the risk of legal problems, which encourages the practice of defensive medicine.

- Prevent religious or philosophical beliefs from. ה̄egatively influencing the doctor-patient relationship.

- Ensure academic independence of medical groups or societies in the development of continuing medical education programs or congresses, which should be free of promotional influence of the pharmaceutical or medical supplies industry.

- Notice in scientific journals any possible bias of clinical trials funded by the industry, as a possible limitation in information that can distort genuine medical-scientific interest. 